\title{
Low-Frequency Sound Proof Cement-Based Syntactic Foam
}

\author{
Norwanis Hasan, Syed Fuad Saiyid Hashim, and Zulkifli Mohamad Ariff
}

\begin{abstract}
A low frequency soundproofing cement based material has been developed in this study. This closed-cell composite material basically consists of a cement matrix embedded with in-house developed Cement Spheres (SC) and Cement Hollow Sphere (CHS) or macrospheres. The produced foams known as Cement Syntactic Foam (CSF) were characterized for its' properties including stress-strain behaviour. Acoustic Transmission Loss (TL) test was conducted on two types of CSF, namely CSF-CS and CSF-CHS and the results were compared to plain cement (PC). It was observed that the CSF showed a good mechanical properties and better sound TL in a low frequency range. The significant improvement in the TL was shown by CSF with incorporating CHS. However, no significant increase in the TL was observed with the increasing sample thickness. Overall, it was discovered the produced CSF has potential in the application of lightweight soundproofing material substituting common barrier material.
\end{abstract}

Index Terms-Soundproofing cement based material, closed-cell composite, cement syntactic foam, transmission loss.

\section{INTRODUCTION}

The study of acoustic insulation in a building are commonly attempted to determine sound transmission loss (TL) through different structural design. Common barrier materials used in structural design to impede exterior noise are gypsum board, plywood and concrete. Most of the studies in the literature are focussing on the construction of these materials that usually comprise one or more layers board on each side [1]-[4]. To improve the sound insulation, the installation of sound absorbing materials in the partition cavity was studied [2]. Presently, many researches are being conducted from the viewpoint of constructing the structural design within a building walls, but few have paid attention to enhance the TL by incorporating smart materials. This study is carried out to develop innovative closed-cell cement foam known as cement-based syntactic foam (CSF), as a soundproof material.

This totally closed-cell composite material basically consists of a cement matrix embedded with in-house developed macrospheres. The macrospheres in the CSF can avoid the air-borne sound from passing through since the foam cell wall are enclosed by rigid shells. Thus, this closed-cell foam have a great potential as a sound proofing material compare to cellular cement foam, that normally have

Manuscript received January 10, 2013; revised March 20, 2013.

Norwanis Hasan and Syed Fuad Saiyid Hashim are with School of Materials and Mineral Resources Engineering, USM Engineering Campus, 14300 Nibong Tebal, Penang, Malaysia (email: nnis09@yahoo.com)

Zulkifli Mohamad Ariff is with Universiti Sains Malaysia, Seri Ampangan, 14300, Nibong Tebal, Seberang Perai Selatan, Penang, Malaysia, (email: zulariff@eng.usm.my). low damping due to the open and interconnected cell structure. The adding of macrospheres also helped in reducing weight, thus lower the density . Unlike other assembly wall materials, the CSF does not rely on the mass law. The mass law equation [3], predicts that each time the frequency of measurement or the mass per unit area of a single layer wall is doubled, the TL increases by about $6 \mathrm{~dB}$. The mass per unit area can be increased by increasing thickness or by selecting a more dense material. However, this study found otherwise and similar observations were found in a closed-cell aluminium foam [4], [5].

Therefore, in comparison to conventional concrete, the CSF has the advantages of low density, low water absorption, good mechanical strength and damping properties. Moreover, the addition of macrospheres, provide better energy absorbing mechanism, thus improving the compressive toughness of the system. Because of its special feature, this study was carried out to study the potential of the prepared CSF in sound proofing application.

\section{EXPERIMENTAL}

\section{A. Materials}

Portland cement type I manufactured by CIMA Industries Sdn. Bhd. was used as the matrix. Clear epoxy resin (DER 331) and polymer hardener (Crystal clear 8161) formulated with 2:1 supplied by Euro Chemo-Pharma Sdn. Bhd were used as the epoxy coating system for expanded polystyrene beads (EPB) during the preparation of macrospheres.

\section{B. Preparation of Macrospheres}

Two types of macrospheres were prepared in this study, i.e. cement sphere (CS) and cement hollow sphere (CHS). EPS beads with ranges of sizes $(3-4.5 \mathrm{~mm})$ were used as intermediate materials to develop the spheres. The epoxy resin system prepared as mentioned above was mixed together with the EPS beads in a ratio of 1:30 by volume. They were continuously mixing initially until all EPS beads were fully coated. Then, they were transferred onto a tray filled with sufficient amount of cement powder and quickly the beads were separated from each other. This step ensured that the uncured epoxy-coated beads was fully coated with cement powder and thus prevented the beads from clumping each other. These epoxy-cement coated beads were then cured in an oven for 15 minutes at $80^{\circ} \mathrm{C}$. At this stage, the produced sphere together with the EPS beads within the shell were designated as cement sphere (CS). While for the production of cement hollow sphere (CHS), the produced CS were subjected to post-curing process at $120^{\circ} \mathrm{C}$ for a further 60 minutes to shrink all the EPS beads. 


\section{Cement Syntactic Foam (CSF) Preparation}

The shape and dimensions of cement syntactic foam (CSF) samples were prepared according to testing procedures that are going to be submitted to the samples. Particularly, cylindrical samples (100 mm diameter and $150 \mathrm{~mm}$ high) were prepared for the acoustic characterisation and square samples $(70 \mathrm{~mm} \times 70 \mathrm{~mm} \times 70 \mathrm{~mm})$ were meant for compression test. The fabrication process consists of mixing cement and water in a ratio of 0.6 and stirring them until a uniform mixture was obtained. The macrospheres were then filled completely into a pre-determined steel mold and then transferred into a container. A sufficient amount of cement mixture was then poured into the container. The mixture was gently stirred to avoid breakage of the macrospheres and to obtain a uniform dispersion of the macrospheres in the cement matrix. Then, the mixture was poured back into the steel mold A constant pressing force was applied by loading onto the mold lid with a standard weight $(1 \mathrm{~kg})$ to maintain the macrospheres in their well-dispersed state. The samples were cured at room temperature for 24 hours and subsequently removed from the mold.

For the acoustic test, the cylindrical samples were sawn into samples with different thicknesses (10, 20 and $30 \mathrm{~mm}$ ), while for the compression test, the samples were aged in a tap water for 3, 7, 28 and 90 days. The sample mix with CS and CHS were named as CSF-CS and CSF-CHS respectively. Fig. 1 shows these two types of samples used for the acoustic test.

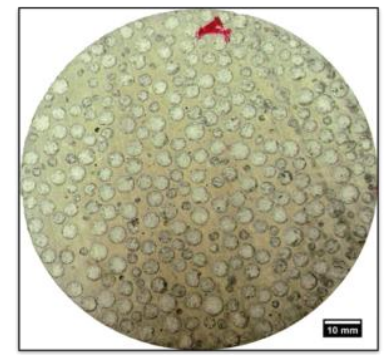

(a)

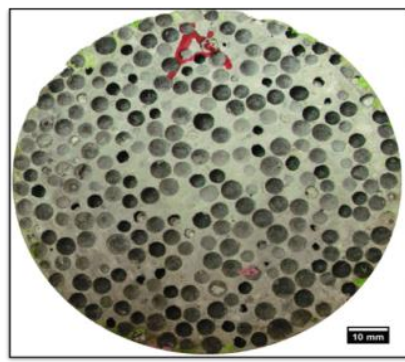

(b)

Fig. 1. Surface structure of (a) CSF-CS and (b) CSF-CHS samples (100 mm in diameter)

\section{Acoustic Test}

Acoustic insulation measurement was implemented by utilizing a methodology based on ISO 10534-2. A four microphone transfer function method was used through the application of impedance tube to determine Transmission Loss (TL). The impedance tube was made of two cylindrical PVC tube having inner diameter of $100 \mathrm{~mm}$, with a sample holder at its middle position as shown in Fig. 2. Two sets of microphones were positioned in the upstream and the downstream of the tube, with a specified distance according to the working frequency. A four channel oscilloscope has been utilized to record the signal from the microphones which was connected to a computer for signal processing.

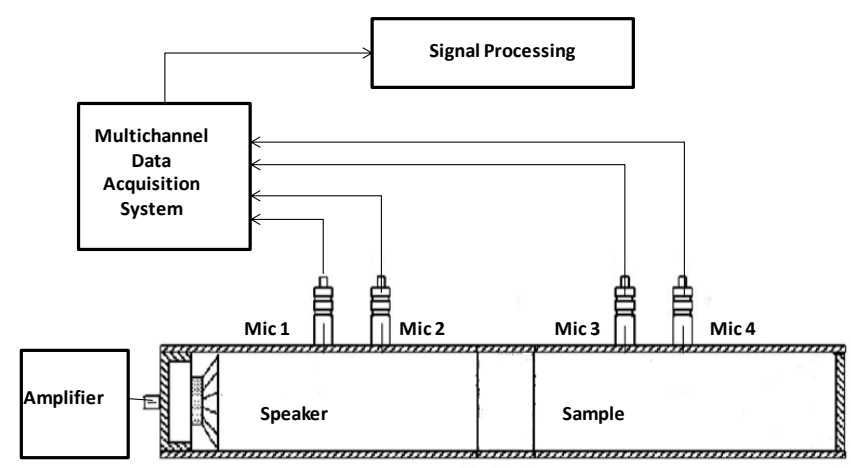

Fig. 2. Impedance tube arrangement with 4 microscope method employed for Transmission Loss measurement.

\section{E. Compression Test}

The compression tests were carried out using a Universal Testing Machine model UHF-1000kNI on 70x70x70 $\mathrm{mm}^{3}$ cubes samples. BS standard EN 679 was adopted to measure the compressive strength. The rate of cross head movement was maintained at $0.5 \mathrm{~mm} / \mathrm{min}$. For each type of cement syntactic foam, at least four samples were tested.

\section{RESULTS AND DISCUSSIONS}

The average density of the CSF is $895.7 \pm 26.0 \mathrm{~kg} / \mathrm{m}^{3}$ while, the measured density of plain cement (PC) is $1635 \mathrm{~kg} / \mathrm{m}^{3}$. In this study, the density of CSF-CS and CSF-CHS are assumed to be the same as the expanded polystyrene beads (EPB) in the $\mathrm{CS}$, with its low mechanical properties, does not contribute significantly to the mechanical properties of the composite [6], thus giving very little or no effect to the density of the CSF.

\section{A. Compression Test}

A comparison of variation in compressive strengths after 3 , 7,28 and 90 ageing days were given in Fig. 3. The variation of compressive strength with ageing period shows that there is a continuous increase in the compressive strength up to 90 days but the rate of gain in compressive strength varies slightly. This phenomenon may be due to the compatibility between the CHS and the matrix as they are made from the same material and in constant volume fraction throughout the experiment.

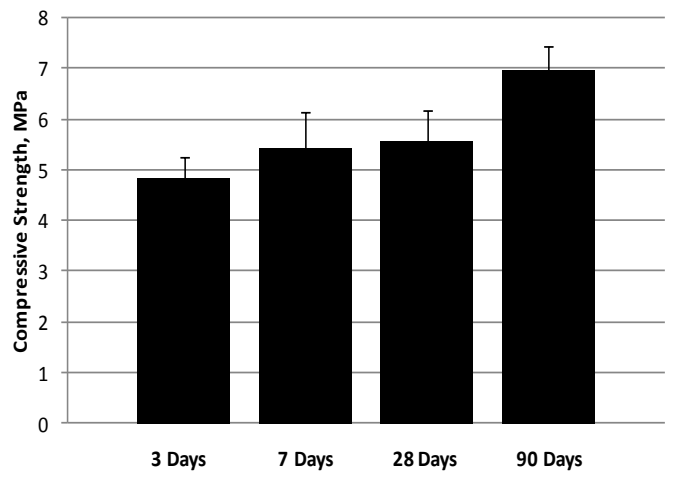

Fig. 3. Variation of compressive strength with age and density 


\section{B. Stress-Strain Curve}

The compressive stress-strain curve of the CSF is shown in Fig. 4. It is observed from the curves that, CSF deformed elastically at the beginning until the stress reached the maximum compressive stress. After reaching the peak stress, the stress suddenly dropped and exhibited a plateau. This plateau region corresponds to the process of compressing hollow spheres during compression thus giving rise in energy absorption [6], [7]. When significant fraction of the available hollow spheres have collapsed, further deformation results in densification and it is detected as visible upward trend of the curve. From the stress-strain curve above, it was found that, the addition of CS and CHS in the CSF contributed to better energy absorbing capability, thus increasing toughness of the system.

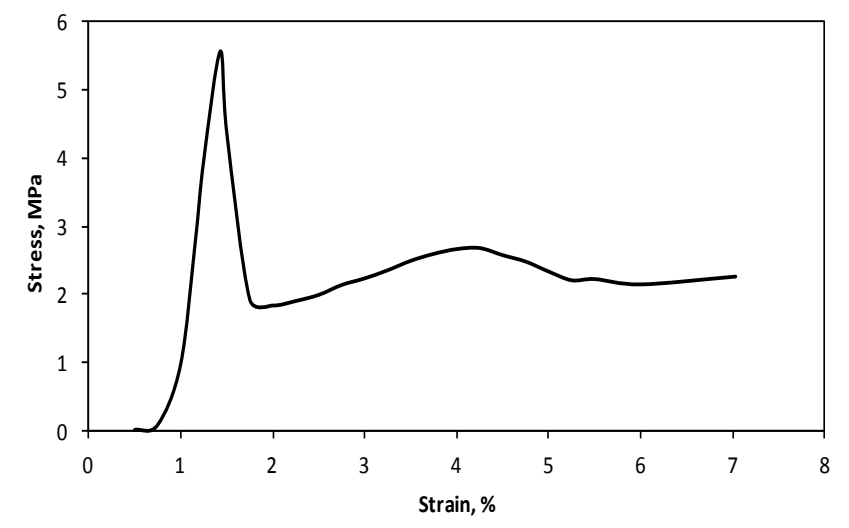

Fig. 4. Compressive stress-strain curve of CSF

\section{Acoustic Properties}

Fig. 5 shows the sound transmission loss comparison among the plain cement (PC), CSF-CS and CSF-CHS having the thickness of 10, 20 and $30 \mathrm{~mm}$. Apparently, the TL behaviour for the PC, CSF-CS and CSF-CHS exhibited similar pattern. The TL increment for all samples are approximately the same up to $300 \mathrm{~Hz}$, before slightly decreasing above the frequency. However, it is clearly seen that the CSF-CHS shows significant improvement in acoustic insulation. Whereas, CSF-CS shows increment in TL for 10 mm sample thickness but exhibited more or less similar behaviour with the PC sample for $20 \mathrm{~mm}$ and $30 \mathrm{~mm}$ of the sample thickness. As the previous studies [8], [9] supported by the mass law indicated that the TL increases in the dense material due to the high flow resistance, the present study found otherwise. The CSF sample, though having less density compared to the PC sample, showed better sound transmission loss. The closed-cell structure in the CSF, prevented the passage of air, giving high resistance to the sound wave to travel as well as the PC, but has compromised in the material density. While the significant improvement of the TL in CSF-CHS compare to CSF-CS, can be attributed to the present of open porosity combined with rough internal pore on its surface. The rough and porosity structure allows considerable sound wave dissipation via friction when it is in contact with the CSF-CHS surface sample, thus, giving rise in the TL as shown in Fig. 5.

Fig. 6 shows the TL of CSF-CS and CSF-CHS of different thicknesses. There is no obvious change occurred when the thickness was increased from $1 \mathrm{~cm}$ to $3 \mathrm{~cm}$. According to the previous studies [3], [8], [9], the addition of sample thickness and densities, can increase the surface density of the material which leads to the increase of the TL. However, the CSF already has reasonable sound transmission loss, and further increase in sample thickness would not have increased the TL significantly. Therefore, it can be deduced that both types of CSF were able to satisfy the effective demands of sound insulation requirement, when material economics are taken into consideration.

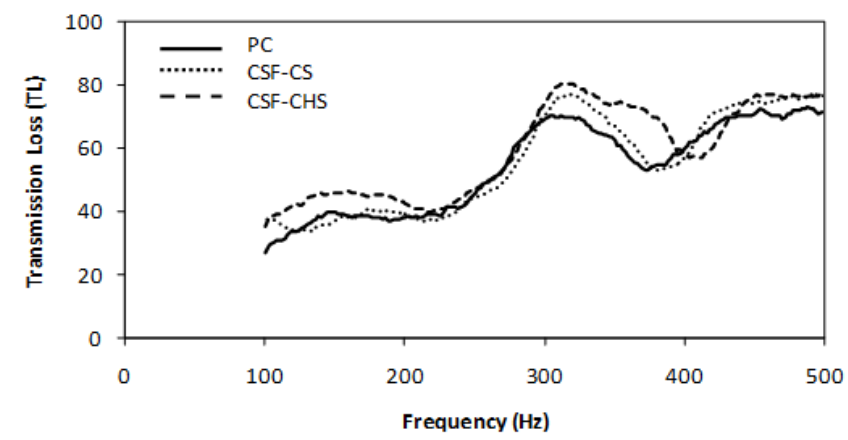

(a)

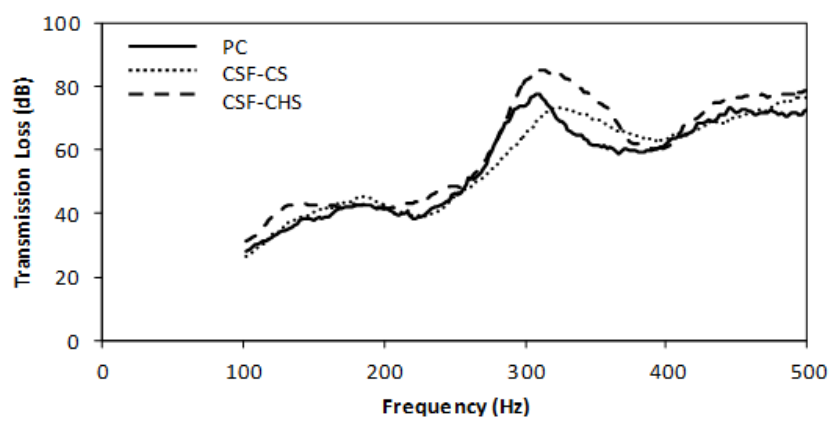

(b)

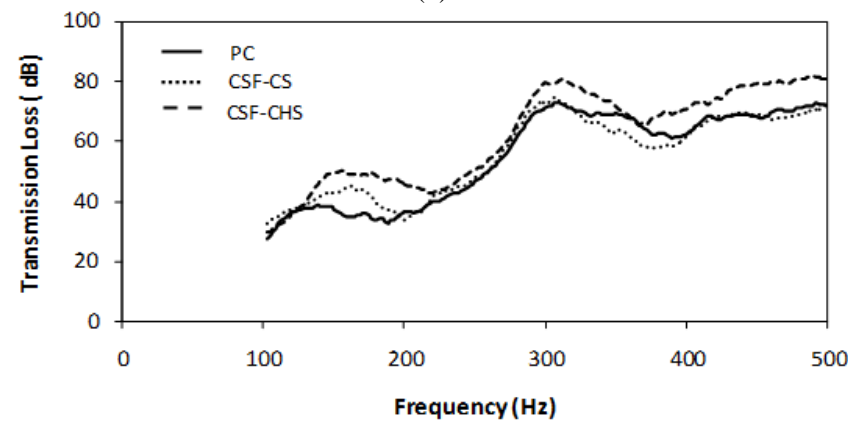

(c)

Fig. 5. Sound transmission loss curves of CSF and PC of (a) $10 \mathrm{~mm}$, (b) $20 \mathrm{~mm}$ and (c) $30 \mathrm{~mm}$

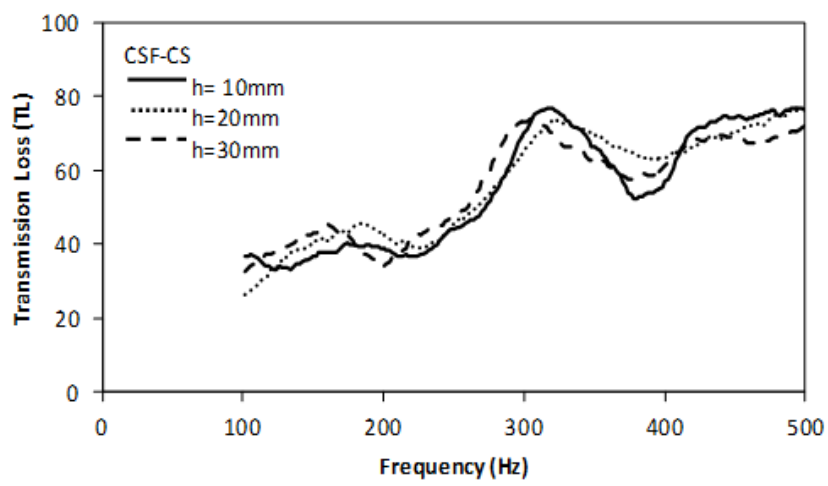

(a) 


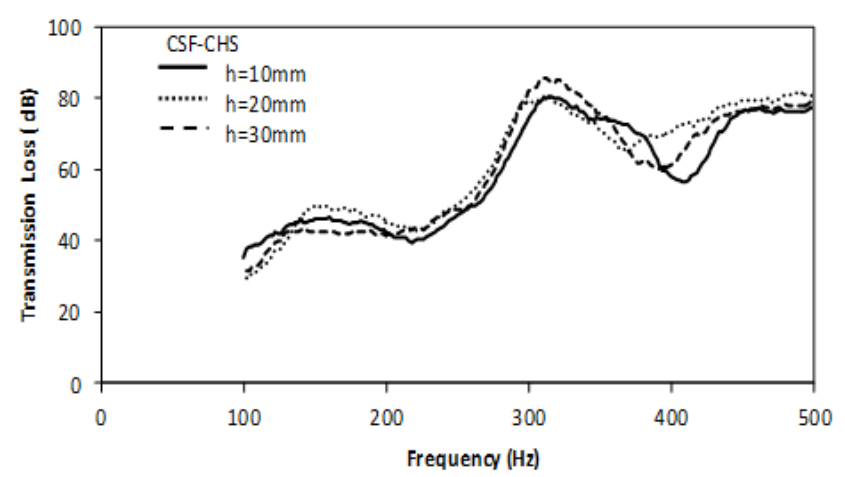

(b)

Fig. 6. Transmission Loss of (a) CSF-CS and (b) CSF-CHS of different thickness

\section{CONCLUSIONS}

The mechanical properties and sound TL behaviour of CSF has been studied. The addition of macrosphere in the CSF have advantages of low density, increasing the toughness and fine damping compare to PC. The sound TL performance of the CSF can be significantly improved by introducing open porosity and rough internal pores on its' surface as shown by CSF-CHS. While, the addition of sample thickness does not improve the sound TL, thus, considering practical application CSF of $10 \mathrm{~mm}$ can demonstrates good sound insulation. In conclusion, the CSF prepared in this study have potential as a low-frequency soundproofing lightweight material.

\section{ACKNOWLEDGMENTS}

The financial support of the Research University Postgraduate Research Grant Scheme by Universiti Sains Malaysia under grant numbers 1001/PBAHAN/8042016 and $\mathrm{MyPhD}$ via MyBrain 15 Programme under Ministry of Higher Education, Malaysia, are gratefully acknowledged.

\section{REFERENCES}

[1] I. Guillen, A. Uris, H. Estelles, J. Llinares, and A. Llopis, "On the sound insulation of mansory wall facades," Building and Environment, vol. 43, pp. 523-529, Jan. 2007.

[2] J. M. Bravo, H. Estelles, J. Llinares, J. Sinisterra, and A. Uris, "Technical note: Comparison of the sound insulation of lightweight partitions with different sound absorbing infills," Building Acoustics, vol. 9, pp. 303-309, Feb. 2002.

[3] A. C. C. Warnock. (July 1985). Factors affecting sound transmission loss. Can Bldg Digests. [Online]. Available: http://web.mit.edu/parmstr/Public/NRCan/CanBldgDigests/cbd239_e .html

[4] H. Yu, G. Yao, X. Wang, Y. Liu and H. Li, "Sound insulation property of Al-Si closed-cell aluminum foam sandwich panels," Applied Acoustics, vol. 68, pp. 1502-1510, Oct. 2006.

[5] H. Yu, G. Yao, X. Wang, B. Li, Y. Yin, and K. Liu, "Sound insulation property of $\mathrm{Al}-\mathrm{Si}$ closed-cell aluminum foam bare board material," Transactions of Nonferrous Metals Society of China, vol. 17, pp. 93-98, Jan. 2007.

[6] T. D. Tonyan and L. J. Gibson "Strengthening of cement foams," Journal of Material Science, vol. 27, pp. 6379-6386, 1992.
[7] N. Gupta and W. Ricci "Comparison of compressive properties of layered syntactic foams having gradient in microballoon volume fraction and wall thickness," Materials Science and Engineering A, vol. 427, pp. 331-342, 2006.

[8] F. Cotana, A. Rossi, Nicolini, and S. Simoni, "Acoustic Test on Original Concrete And Inert Mixture Materials," presented at the $14^{\text {th }}$ International Congress on Sound Vibration, Cairns, Australia, 2007.

[9] A. C. C. Warnock. (May 1998). Controlling Sound Transmission Loss through Concrete Block Walls. Construction Technology Update. [Online].

http://archive.nrc-cnrc.gc.ca/eng/ibp/irc/ctus/ctus-n13.

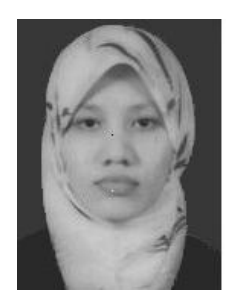

Norwanis H. was born in Perlis, Malaysia in 1979. She received the B. Eng and MSc in mineral resources engineering from the Universiti Sains Malaysia in 2002 and 2008 respectively. She is currently pursuing the $\mathrm{Ph} . \mathrm{D}$ in material engineering at the same university. Her current research covers fabrication of closed-cell syntactic foam including its failure features, mechanical and insulation properties.

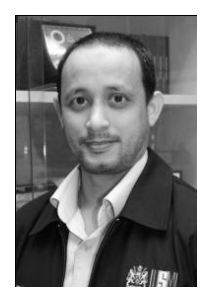

Syed Fuad S. H. was born in Penang, Malaysia, in 1972. He received his B.Eng. and M.Sc degrees in Mineral Resources Engineering from the Universiti Sains Malaysia in 1996 and 1999 respectively. He obtained his Ph.D. from the University of Queensland in the field of Mineral Engineering in 2004.

He then joined the School of Material and Mineral Resources Engineering, Universiti Sains Malayisa as a lecturer and in 2009 he was appointed as Mineral Resources Engineering Programme Chairman. With the achievement made, he then promoted to Associate Professor in 2102. Currently, Syed Fuad SH is the Deputy Dean responsible for academic affairs at School of Materials and Mineral Resources Engineering. His research interests covers, mineral resources engineering, fine grinding, cement manufacturing technology, mathematical modelling and simulation of mineral processing system and recycling.

Assoc. Prof. Dr. Syed Fuad is an engineer registered with The Board of Engineers, Malaysia, a graduate member of The Institution of Engineers, Malaysia (IEM) and member of The Institute of Minerals, Malaysia (IMM). $\mathrm{He}$ was the recipient of the Malaysian Construction Industry Excellence Awards 2004 under the R \& D project of the Year Award by Construction Industry Development Board (CIDB) Malaysia and was awarded various medal in Malaysian Trade and Exposition in 2006, 2007 and 2009.

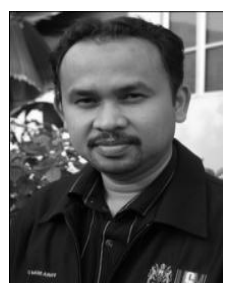

Zulkifli M. A. was born in Perak, Malaysia in 1973 $\mathrm{He}$ received B.Tech degree in polymer technology from the University Sains Malaysia, in 1997, M.Sc. degree in polymer science and technology from the University of Manchester Institute of Science and Technology (UMIST), UK in 1998 and Ph.D. degree in polymer technology specializing in polymer rheology from the University of Science, Malaysia, in 2004.

He has held lecturing positions at University Sains Malaysia, since 2004 and became a Senior Lecturer in 2008 and appointed as an Associate Professor in 2010. He has published more than 30 scientific peer-reviewed international journal papers in several fields of his research interests, including preparation and characterisation of various polymeric foams, polymer melt rheology and real-time measurement of parameter changes during polymer processing.

Assoc. Prof. Dr. Zulkifli is a member of Polymer Processing Society (USA) and editorial board member of Malaysian Polymer Journal published by the Plastics and Rubber Institute of Malaysia. 